\title{
Planum Sphenoidale Meningioma: A Rare Location of Skull Base Meningioma
}

\author{
Patrice LWY Sinaga ${ }^{1}$, Faisal $^{1}$, Ridha Dharmajaya ${ }^{1}$ \\ ${ }^{1}$ Department of Neurosurgery, Universitas Sumatera Utara, Medan, Indonesia
}

\begin{abstract}
Background: Meningioma is common primary central nervous system tumors. Twenty-five percent of all meningioma consist of skull base meningioma. Planum sphenoidale meningiomas are rare. Planum sphenoidale meningiomas can extend into adjacent areas. Approximately two thirds of patients complain of failing vision in one eye as the first symptom.

Case Report: A 32-year-old woman presented with 6-month history of progressively worsening blurred of both of vision. She also complained her smell ability was reduced for 3 months. She had headache for 6 months. The pain was worsening in the morning. She is conscious. A neurologic examination revealed bilateral hyposmia and visual deficits but no weakness. Visus of oculo dextra was 1/300 and visus of oculo sinistra was no light perception. Magnetic resonance imaging (MRI) intravena contrast of brain revealed a large extra-axial mass measured $\pm 6,2 \times 5,9 \times 6 \mathrm{~cm}$ centred on planum sphenoidale displacing both frontal lobes. She had an operation of tumor removal with cranio-orbito-zygotomy approach. The tumor, which measured $\pm 7 \mathrm{~cm} \times 7 \mathrm{~cm} 6 \mathrm{~cm}$, was succesfully removed completely. She gets improvement of smell ability and both visual postoperatively. The histopathology of the tumor revealed meningioma WHO grade I.

Discussion: Planum sphenoidale meningiomas present a frequently encountered pathology of the anterior skull base. These meningiomas give rise to an early visual disturbance with relatively slow progression. Displacement of the olfactory tracts and optic chiasm occur when the meningioma extends into the paranasal sinuses and nasal cavity. Clinical presentation and diagnosis often occur in the late stage. Anosmia is one of common finding on physical examination. Postoperative improvement of visual symptoms depends on the preoperative duration of those symptoms.

Conclusion: Planum sphenoidale meningiomas are rare cases. Headache, visual deficits and impaired smell are common clinical presenting.
\end{abstract}

Keyword: Planum Sphenoidale Meningioma, Visual deficits, Anosmia, Neurooncology

\section{Introduction}

Meningioma account for approximately $36 \%$ of all primary central nervous system tumors, representing the most frequently diagnosed primary brain tumor. Twenty-five percent of all meningioma consist of skull base meningioma.[1] Planum sphenoidale meningiomas are rare, constituting only $2 \%$ of all primary intracranial tumours.[2] They are benign, slowgrowing tumours.[3] Planum sphenoidale meningiomas can extend into adjacent areas such as the diaphragm sellae, posterior clinoid and superior wall of the cavernous sinus. Complete meningioma resection including vascular supply and involved dura and bone may be difficult due to their intimate involvement with these nearby structures. [4] In most patients visual loss has an insidious onset, and the course is progressive. It may, however, be acute or fluctuating.

*Corresponding author at: Department of Neurosurgery,Universitas Sumatera Utara,Medan, Indonesia

Copyright (C) 2020 Published by Talenta Publisher, ISSN: 2686-0848 ; DOI : 10.32734

Journal Homepage: http://aanhsj.usu.ac.id 
Approximately two thirds of patients complain of failing vision in one eye as the first symptom, and monocular blindness may be present in half of the patients before surgery.[5]

\section{Case Report}

A 32-year-old woman presented with 6-month history of progressively worsening blurred of both of vision. First it affects right vision then followed left vision. Left vision is loss. She also complained her smell ability was reduced for 3 months. She had headache for 6 months, which reduced by analgetic. The pain was worsening in the morning. She consequently lost his job as her poor performance. She needed someone to take care of herself. She had no behavioural changes and no past medical history of illness or known exposure to ionizing radiation. She had no known family history of intracranial tumor.

On examination, she is conscious. A neurologic examination revealed bilateral hyposmia with visual deficits and no weakness. Visus of oculo dextra was 1/300 and visus of oculo sinistra was no light perception. Initial blood investigation results (ie complete blood count, glucose level, liver function, renal function, thyroid function test) were normal.

Magnetic resonance imaging (MRI) intravena contrast of brain revealed a large extraaxial mass measured $\pm 6,2 \times 5,9 \times 6 \mathrm{~cm}$ centred on planum sphenoidale displacing both frontal lobes (Figure 1)

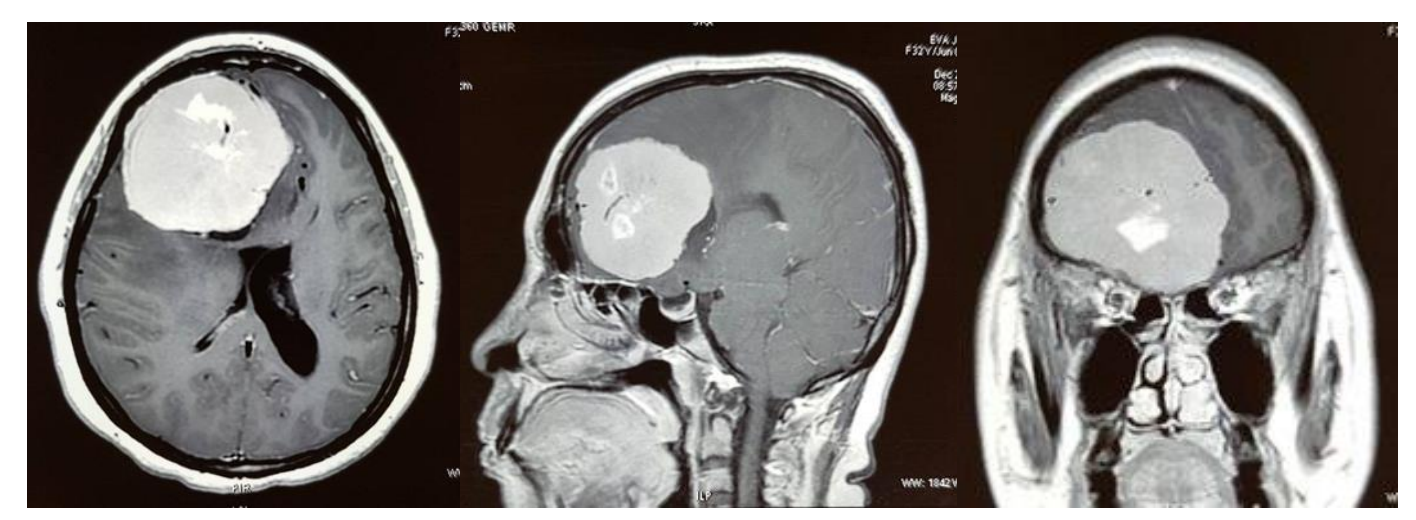

Figure 1. MRI Brain IV Contrast

Mass effect and entrapment of the left lateral ventricle were also visible. She had an operation of tumor removal with cranio-orbito-zygotomy approach (Figure 2). The operation took about 5 hours long. The tumor, which measured $\pm 7 \mathrm{~cm} \times 7 \mathrm{~cm} \times 6 \mathrm{~cm}$, was succesfully removed completely (Figure 3). She was conscious postoperatively. 


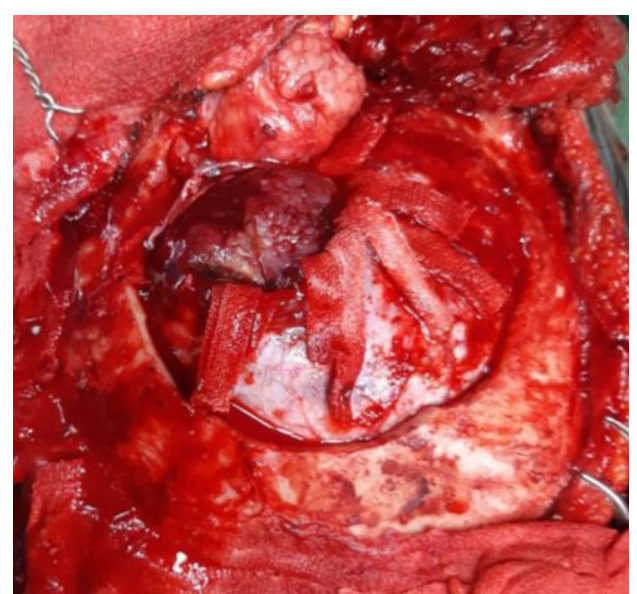

Figure 2. Exposed tumor

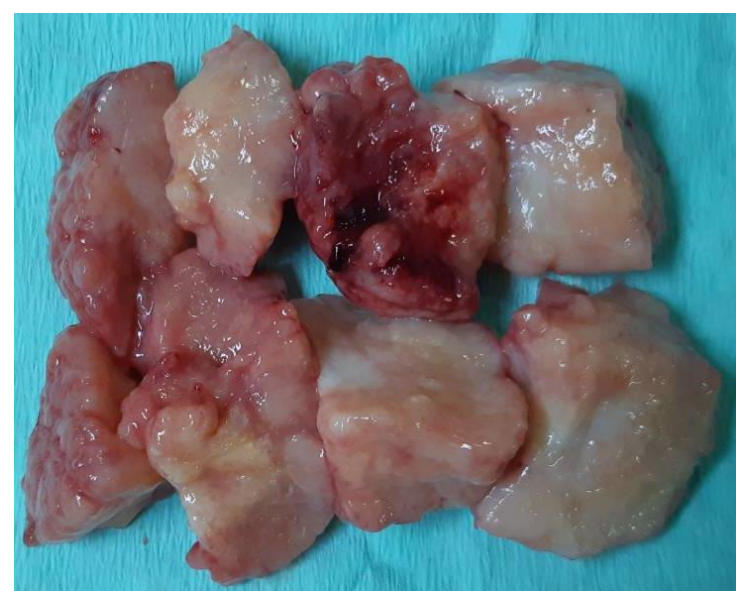

Figure 3. Macroscopic of tumor

Post operatively, the ability of smell was increasing then before even. She had presented both visual improvement that visus of both oculi become 1/60. After 10 days, she went home and followed in outward. The histopathology of the tumor revealed meningioma WHO grade I (Figure 4).

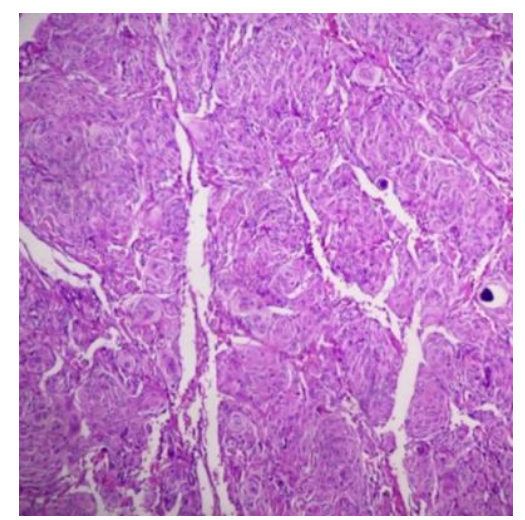

Figure 4. Histopathology

\section{Discussion}

Planum sphenoidale present a frequently encountered pathology of the anterior skull base, representing according to some authors 5 to $10 \%$ of all intracranial meningiomas. [5] These meningiomas give rise to an early visual pathology with relatively slow progression, but due to the fact that other symptoms are missing or are subtle they have a larger tendency to develop undiagnosed for longer periods of time.[6]

Displacement of the olfactory tracts and optic chiasm occur when the meningioma extends into the paranasal sinuses and nasal cavity.[3] Clinical presentation and diagnosis often occur in the late stage, as many patients are asymptomatic before the meningioma reaches a sufficient size $(>4 \mathrm{~cm})$ to compress the frontal lobe and optic nerve or optic 
chiasm.[7] The patient usually presents with dysexecutive syndrome (severe cognitive impairment and profound changes in personality), which is usually first noticed by family members; headache; or visual symptoms. Anosmia is a common finding on physical examination, but it is not a typical presenting symptom.[8] Postoperative improvement of visual symptoms depends on the preoperative duration of those symptoms.[9] Loss of olfactory function is usually permanent.[3] Although MRI is more expensive and less readily available, it is preferred to CT scan.[10]

Similarly, once tumors approach $<6 \mathrm{~mm}$ from the optic chiasm, they are 11 times more likely to cause visual symptoms, implying at first that it might be advisable to operate on a planum meningioma that is 7 to $8 \mathrm{~mm}$ away from optic chiasm even if it is not currently causing visual symptoms. Interestingly, however, distance to the optic chiasm is not an independent predictor of visual symptoms in our multivariate analysis. Only brain tumor volume is an independent predictor of visual symptoms in our multivariate model. Although this may result from our relatively limited sample size and we certainly believe it is advisable to consider the proximity to the chiasm in treatment decision planning, our data raise the possibility that it not contact with the optic nerve alone that causes visual symptoms but rather overall tumor bulk. Patients with large tumors may have chronic papilledema from increased intracranial pressure leading to nerve loss and optic atrophy on funduscopic examination.[11]

Some patients may present first with visual loss and acute hemorrhagic papilledema leading to rapid visual decline from ischemic optic to rapid visual decline from ischemic optic neuropathy. Some of these patients will have continued visual decline after removal of their tumors from the irreversible ischemic proscess at the optic nerve head that surgical decompression cannot immediately reverse, which suggests that it is important to follow visual function and field in patients with preoperative visual loss, which was not done systematically in our series because of referral patterns.[11]

\section{Conclusion}

Planum sphenoidale meningiomas are rare loacation of skull base meningioma. Headache, visual deficits and impaired smell are common clinical presenting. Postoperative improvement depends on preoperative duration of symptoms. 


\section{References}

[1]. Mortazavi, MM, Silva, HB, Ferreira, M, Barber, JK, Pridgeon, JS, Sekhar, LN. Planum Sphenoidale and Tuberculum Sellae Meningioma: Operative Nuances of a Modern Surgical Technique with Outcome and Proposal of a New Classification System. World Neurosurg. 270-285. 2016.

[2]. McDermott MW, Wilson CB. Meningiomas. In: Winn HR, Youmans JR, editors. Youmans neurological surgery. 4th ed. Vol 1. Philadelphia, PA: WB Saunders Company; 1996. p. 2782-825.

[3]. Chiang, GSH, Goh, LG. Olfactory groove and planum sphenoidale meningioma. Case Report. Canadian Family Physician. 2017.

[4]. Gardner PA, Kassamm AB, Thomas A, Snyderman CH, Carrau RI, Mintz AH, et al. Endoscopic endonasal resection of anterior cranial base meningioma. Neurosurgery. 2008; 63:36-52; discussion 52-54.

[5]. Balasa, A, Chinezu, R, Gherasim, DN. Surgical Management of Tuberculum Sellae Planum Sphenoidale Meningioma. Neurosurgery Department, Targu Mures Clinical Emergency Hospital. Romanian Neurosurgery (2013) XX 1:92-99. 2013.

[6]. Fahlbusch R, Schott W: Pterional surgery of meningiomas of the tuberculum sellae and planum sphenoidale: surgical results with special consideration of ophthalmological and endocrinological outcomes. J Neurosurg. 2002 Feb;96(2):235-43.

[7]. Ojemann RG. Olfactory groove meningiomas. In: Al-Mefty O, editor. Meningiomas. New York, NY: Raven; 1991. p. 383-93.

[8]. Nakamura M, Struck M, Roser F, Vorkapic P, Samii M. Olfactory groove meningiomas: clinical outcome and recurrence rates after tumor removal through the frontolateral and bifrontal approach. Neurosurgery 2007;60(5):844-52.

[9]. Andrews BT, Wilson CB. Suprasellar meningiomas: the effect of tumor location on postoperative visual outcome. J Neurosurg 1988;69(4):523-8.

[10]. Moore A, Patterson C, Lee L, Vedel I, Bergman H. Fourth Canadian Consensus Conference on the Diagnosis and Treatment of Dementia. Recommendations for family physicians. Can Fam Physician 2014;60:433-8 (Eng), e244-50 (Fr).

[11]. Zygourakis, CC, Sughrue, ME, Benet, A, Parsa, AT, Berger, MS, et al. Management of Planum/Olfactory Menigioma: Predicting Symptoms and Postoperative Complication. World Neurosurgery Journals. Elsevier. 2014. 